\title{
The Research on Color Words Teaching in Teaching Chinese as a
}

\section{Foreign Language}

\author{
Kunhu $\mathrm{Wu}^{1, \mathrm{a}}$ \\ ${ }^{1}$ College of Literature and Law, Sichuan Agricultural University, Ya'an, Sichuan, 625014 \\ ${ }^{\mathrm{a}}$ email
}

Keywords: Color Words, Teaching Chinese as a Foreign Language, Cultural Meaning

\begin{abstract}
Color words and culture are closely related. People with different cultural backgrounds will have different understanding of the meaning of color words. This paper firstly analyzes the important significance of color words in teaching Chinese as a foreign language, and gives some suggestions on teaching color words in teaching Chinese as a foreign language. This paper, from the perspective of color words teaching, gives a little inspiration to the teaching of cultural vocabulary.
\end{abstract}

\section{Introduction}

The colors constitute a colorful world. The color words reflect the magnificent colors in the language. Every nation has the color words reflecting and recording the colors. Due to the differences in many aspects of the nation's geography, customs, religion, values, and cultural background, bearing the color words in different national culture are quite different. Chinese color word has a unique and rich cultural connotations, in teaching Chinese as a foreign language, students if the correct understanding of the cultural connotation of color words in Chinese, can reduce communication misunderstanding and improve cross cultural communicative competence. Basic color terms reflect the color is the most common people's life, the most commonly used color, the understanding of Chinese basic color words, select the use of high frequency color words, can make the color words in teaching Chinese as a foreign language teaching more scientific and pertinence. Color is a perception of the objective world. People's different visual senses of color make people have different types of color words. This is a phenomenon, is a kind of language with a color to describe the object, in another language does not use the same color to describe. There are a number of common sets of eleven types of colors in the world. Select a group from each language. Due to too many classifications of color words, the meaning of color words is fuzzy. The classification of color words is based on people's subjective feelings, and is different from the optical classification, so the definition of color words in daily life is vague and imprecise.

\section{Significance of Color Words Teaching in Teaching Chinese as a Foreign Language}

High Application Frequency. Color words are an important part of Chinese vocabulary. It is like a magic pen, painted the color of the language world, so that the whole language world alive. The use of color words in Chinese can be seen everywhere. Foreign language teaching is the teaching of Chinese as a second language. For second language learners, not only to master the pronunciation, vocabulary and grammar of the target language and formal language basic knowledge, also need to understand language form that contains the cultural communication and the language form of expression of customs, values, attitudes and other cultural knowledge. To truly understand or study a culture, it is necessary to master the language of the cultural symbol, and to 
acquire and use a target language. We must learn the culture of the language at the same time. Color words in different languages will be more or less different. The students have good language skills and knowledge of color words of mother tongue in already ingrained exist in their minds. They are very easy to mother tongue color word knowledge move directly into the Chinese, while ignoring the characteristics of Chinese color words.

Deep Cultural Implication. As a result of different perception of different nations and countries for colors, color words reflect the different nations, countries respective cultural traditions, social customs and habits of thought in a certain extent. At the beginning of the birth of human beings, color is a help people to recognize the alternation of day and night, give survival enlightenment, so that people know the day and hunt for food at night to avoid injury. When more and more people know things, people know and master the color words are more and more, and began to originally without distinction of color added their likes and dislikes, appraise and emotional evaluation. For example: in the night, the beast to attack, to people's life is a threat, so people do not like the advent of the night. This makes black to be an unpleasant color. Because people have learned to use the fire to drive away the beast and heating, red and fire color is very similar. Red has been the people's favorite. With the development of society, the emergence of different nationalities, different countries, making people more profound understanding of the color of the word. At this time, the color words are not only classified according to people's preferences, but also carry a national, National People's understanding of the natural things, aesthetic, ethical and philosophical thinking. Color words in the role of culture also produced a sense of association, resulting in the association of color words meaning, which makes the color words in different cultures also showed great differences in the application. Color words are closely related to culture. So in the use of color words, we should ensure to pay attention to the color words under the cultural influence in the different countries.

\section{Principles of Color Words Teaching in Teaching Chinese as a Foreign Language}

Stress Cultural Meaning. Chinese color words reflects the way of thinking of the Han nationality and all sorts of cultural precipitation. If we do not understand the difference between them and attached to the Chinese cultural significance, it will cause foreign students one-sided word meaning acquisition, and ultimately affect the communication, even cultural conflicts. Therefore, the topic of Chinese cultural vocabulary teaching, to help students more systematic grasp of them, is very valuable. Chinese teachers to explain to the color of Chinese words, in addition to the basic meaning, but also should be in the dissemination of Chinese culture concept, to further explain the cultural meaning of color words, pay attention to the daily life of culture. After introducing the color, guide them to think about the daily life of some of the color phenomenon, so that students will color and their daily life of the common things in contact and comparison. Red can be associated with China's festive season. The teacher can explain it by drawing and so on. To guide students to think about the impact of foreign culture on Chinese culture, and teachers should encourage them to discover the cultural diversity of China. Chinese rich cultural meaning of the word has many, such as digital words, homonym words, animal and plant words and so on, we selected the color word because any kind of language, the amount of color words is by the cultural factors, the semantic refers to often also because of the cultural background of different characteristics and show a different. In the Chinese and Western culture, there is a huge cultural difference of the color words. Compared with Chinese culture, the red in the western culture is a quite derogatory word. Red in English is a symbol of brutality and bloodshed. The red in Chinese represents the prosperity and development. 
Apply Multi-media Teaching. When explaining the color words, teachers can use the picture to combine the color words with specific objects, so that students can better identify the color words, with pictures and sounds of the auxiliary will also increase the accuracy of understanding. In addition, using multimedia teaching as a supplementary means can also increase the interest and authenticity of the classroom, so that students learn more about the color of the word image. For example, we can produce a picture of the rainbow in the classroom, first of all, the beautiful rainbow will attract the attention of students, stimulate students want to use Chinese to describe the desire. Students can intuitively recognize each color. Again, the rainbow is a complete image, helps students more quickly memorize all the color words. We can also give students a full color display, and with a clear explanation, the students can be based on the picture to repeat the contents of their own to hear, as far as possible to use the language of learning Chinese color words to express. In addition, the multimedia teaching in some extent reduce the workload of teachers, as long as teachers to prepare in advance to do courseware, will be handy in the classroom teaching, according to the predetermined program to organize the classroom teaching, compared to the traditional classroom teaching can save teaching time and does not require teachers to spend a lot of time to writing on the blackboard, to leave students more time to practice and make classroom teaching to optimize the allocation of resources effect. For example, in learning color words in writing, we can advance in the courseware produced color words writing stroke order, teacher side commentary side let students describe, let the students to shape and stroke order leave more deep impression saving at the same time, the time to write on the blackboard.

Strengthen Students Practice. As the color words belong to the cultural words, the interpretation is different from the general interpretation of the words. And, the practice is quietly important. Normally, we are of the view that in the classroom to the students themselves sentences would be a waste of time, so teachers to lead students to do exercises. Practice, you can give the first half of the sentence, and then let the students to add the second half sentence, so as to complete the whole sentence. In addition to ones of use sentences of this form of exercise, you can try a conjunction into a sentence, or conjunctions into a section of the way, like this will let the students for the use of the term and impression in the understanding of meaning is more profound. For practice, teachers can take a more diverse and flexible approach to the students of different nationalities, and give full play to the subjectivity of the individual, but also conducive to active classroom atmosphere. The teacher is not involved in explaining the color words. This is the present situation of color words in teaching Chinese as a foreign language. Because there is no unified culture teaching syllabus, the teaching of cultural words such as color words is also carried out with the teacher's own teaching plan. In the process of teaching, the teacher can only judge the importance of the word by his own experience, and then explain the importance of the word. However, this choice also tends to result in the loss of students' knowledge. In view of the phenomenon that the students use color words often go wrong, the teacher can take some effective training measures to increase the chances of students' practice. After many exercises, students can master the color word more skilled.

Develop Special Test. With the development of Chinese as a foreign language, all kinds of teaching tests are in an endless stream. However, so far, there is not a kind of test mechanism for the cultural vocabulary such as color words. The purpose of teaching is to enable students to apply the knowledge point of learning, and cultural words such as color words are different from the general vocabulary test. Therefore, the mastery of this kind of words can only be understood through a special way. The particularity of the vocabulary, it is necessary to test for this kind of vocabulary is also different. We mentioned above that the color words should be a system of 
professors, and should not be chaotic. Accordingly, there should be a special test for this kind of words to cooperate with the system of teaching. If you do not train the system, it will be a mistake to confuse the meaning of the questionnaire. When the five color words and meaning mixed together, the students will feel very confused and at a loss. In order to avoid this situation again, so that students can really master the color word and its meaning, special test is very necessary. This special test can be divided into two major aspects, one is the basic meaning of words, and the second is the association of words meaning. Test questions can be the choice questions which students are most familiar with. The choice questions have certain drawbacks. Teachers can transform the test questions according to the need to achieve the purpose of the test.

\section{Conclusion}

Vocabulary teaching runs through the whole process of the teaching Chinese as a foreign language. Color words reflect China's long history, unique culture and colorful folk customs. They not only have the characteristics of general vocabulary, but also have special cultural meanings. At present, the color words teaching in teaching Chinese as a foreign language has not received enough attention. Teachers should take effective methods to strengthen and improve the teaching of color words to cultivate the high-quality and cross-cultural talents.

\section{References}

[1] Zhao Ming, Journal of Yunnan Normal University (Teaching and Research on Chinese as a Foreign Language), Vol. 10 (2012) No 4, p.56-62

[2] Zhu Shuyi, Journal of Handan College, Vol. 25 (2015) No 9, p.94-96

[3] Dong Lina, Zhou Mingqiang, Journal of Shaoxing University, Vol. 34 (2014) No 1, p.90-95

[4] Xie Jingyi, Journal of Fujian Agriculture and Forestry University (Philosophy and Social Sciences), Vol. 15 (2012) No 4, p.110-112 